\title{
Thyroglossal duct cyst carcinomas: is there a need for thyroidectomy?
}

\author{
Alexandra Chrisoulidou, ${ }^{1}$ Paschalia K. Iliadou, ${ }^{1}$ Eleni Doumala, ${ }^{1}$ \\ Lemonia Mathiopoulou, ${ }^{1}$ Maria Boudina, ${ }^{1}$ Maria Alevizaki, ${ }^{1}$ Frideriki Patakiouta, ${ }^{2}$ \\ Ekaterini Xinou, ${ }^{3}$ Kalliopi Pazaitou-Panayiotou ${ }^{1}$
}

${ }^{1}$ Department of Endocrinology and Endocrine Oncology; ${ }^{2}$ Department of Pathology, ${ }^{3}$ Department of Radiology, Theagenio Cancer Hospital, Thessaloniki, Greece

\begin{abstract}
OBJECTIVE: Thyroglossal duct cyst (TGDC) carcinoma is a rare entity and its management is controversial. The aim of this retrospective study was to: (a) identify patients with TGDC carcinoma followed up in our clinic and (b) study specific characteristics of the disease and their association with thyroid carcinoma. DESIGN: Medical files of patients with TGDC carcinoma were reviewed and tumour characteristics, lymph node metastases, treatment and follow-up were evaluated. RESULTS: A total of 6 patients, 4 females and 2 males, mean age 39.3 years (median 33.5), were treated for papillary thyroid carcinoma arising in a TGDC. Carcinoma of the thyroid gland was found simultaneously in 4 of these patients, while in one patient thyroid carcinoma developed 10 years after the diagnosis of TGDC carcinoma. A variable clinical picture and presentation was recorded. The most aggressive manifestation of the disease in terms of local infiltration, local recurrence and lymph node metastases was observed in our youngest patients. CONCLUSIONS: Long-term follow-up is necessary for patients with thyroid carcinoma arising in a TGDC. In view of the frequent co-existence of thyroid cancer in these patients, we would recommend detailed thyroid evaluation and, eventually, total thyroidectomy at initial diagnosis of TGDC carcinoma.
\end{abstract}

Key words: Papillary carcinoma, Thyroglossal duct cyst, Thyroid cancer

\section{INTRODUCTION}

A thyroglossal duct cyst (TGDC) arises as a cystic

Address for correspondence:

Kalliopi Pazaitou-Panayiotou, M.D., Ph.D., Head,

Department of Endocrinology \& Endocrine Oncology,

Theagenio Cancer Hospital, Thessaloniki, Greece,

Tel.: +30 2310 898618, Fax: +302310 898809,

e-mail: kpazaitou@in.gr

Received 26-04-2012, Accepted 26-10-2012 expansion of a remnant of the thyroglossal duct tract, its incidence in post-mortem material being $7 \% .{ }^{1}$ The incidence of primary carcinoma within the TGDC ranges from $0.7 \%^{2}$ to $1.6 \%$ of all patients operated on for TGDCs, although the latest published series reports a higher rate of $6.5 \%$ ( 9 patients with TGDC carcinomas were found among 139 patients with thyroglossal duct cysts). ${ }^{4}$ The most common tumour $(90 \%)$ found in TGDCs is papillary carcinoma, followed in 
decreasing frequency by squamous cell carcinoma, follicular, Hürthle cell, insular or, rarely, anaplastic thyroid carcinoma. Medullary carcinoma has not been described, as $\mathrm{C}$ cells are not found in the median thyroid and are thus absent in the thyroglossal duct. ${ }^{3}$

Simple cyst excision results in a 30-60\% recurrence rate. ${ }^{5}$ Therefore, Sistrunk's procedure, consisting of excision of the cyst, the body of the hyoid bone and a core of tissue around the thyroglossal tract through the muscles of the tongue up to the foramen caecum, is recommended. With this procedure the recurrence rate is lower, in the order of $3-10 \% .{ }^{6}$ Moreover, Sistrunk's procedure is considered as the minimum surgical strategy for papillary carcinoma arising in TGDCs. ${ }^{7,8}$

Carcinoma of the thyroid gland is found in $27 \%$ to $56 \%$ of patients diagnosed with TGDC carcinoma. Two theories have been developed regarding its origin: the first theory supports the de novo occurrence of cancer in the TGDC, while the second proposes that TGDC carcinoma may represent a metastasis from a focus of cancer within the thyroid. ${ }^{4}$ As a result, there is no consensus as to whether total thyroidectomy should be performed immediately after initial diagnosis of a carcinoma arising in a TGDC. Total thyroidectomy would allow appropriate follow-up of the patients, ${ }^{2,9,10}$ although some authors do not recommend this procedure on a routine basis. ${ }^{7,8,11,12}$

Given the rarity of the disease and the fact that the clinical picture may vary at presentation, we reviewed a series of 6 cases with TGDC carcinoma treated at our hospital. In each case, the principal features of the patient's history are presented.

\section{PATIENTS - METHODS}

The medical records of 1770 patients with follicular cell derived thyroid cancer were reviewed. Among those, 6 patients with carcinoma arising in a TGDC (all of the papillary type) were identified (4 females, 2 males). The mean age of the patients was 39.3 years (median 33.5, range 18-68 years). Five out of the 6 patients also had papillary carcinoma of the thyroid: in 4 the diagnosis was made simultaneously with the TGDC carcinoma; interestingly in one patient the thyroid cancer developed 10 years after the diagnosis of TGDC carcinoma. Post-operatively, all patients received thyroxine therapy to suppress TSH and were treated with radioactive iodine (RAI). The clinical characteristics of the patients and the histological characteristics of the tumours are shown in

Table 1. Clinical and histological characteristics of patients

\begin{tabular}{|c|c|c|c|c|c|c|c|c|c|c|}
\hline Patient & Sex & Age & $\begin{array}{l}\text { TGDC Ca } \\
\text { size }(\mathrm{mm})\end{array}$ & $\begin{array}{c}\text { Interval to } \\
\text { thyroidectomy }\end{array}$ & $\begin{array}{l}\text { Number of } \\
\text { operations }\end{array}$ & $\begin{array}{l}\text { Thyroid Ca } \\
\text { size }(\mathbf{m m})\end{array}$ & $\begin{array}{c}\text { Lymph nodes } \\
\text { metastases }\end{array}$ & $\begin{array}{c}\mathrm{RAI} \\
(\mathrm{mCi})\end{array}$ & $\begin{array}{l}\text { Follow-up } \\
\text { (years) }\end{array}$ & $\begin{array}{l}\text { Last TG stimulated } \\
(\mathrm{ng} / \mathrm{ml})^{* *}\end{array}$ \\
\hline 1 & $\mathrm{M}$ & 18 & 8 & 10 years & two & $\begin{array}{c}9 \\
\text { Invasive }\end{array}$ & no & 100 & one & 0.57 \\
\hline 2 & $\mathrm{~F}$ & 21 & NA & $\begin{array}{l}\text { Simultaneous } \\
\text { removal }\end{array}$ & two & $\begin{array}{l}\text { no cancer } \\
\text { was found }\end{array}$ & no & $\begin{array}{c}250^{*} \\
(2 \text { doses })\end{array}$ & nine & 0.39 \\
\hline 3 & $\mathrm{~F}$ & 18 & NA & 1 month & two & $\begin{array}{c}\text { multifocal } \\
5\left(1^{\text {st }} \text { tumor }\right) \\
3\left(2^{\text {nd }} \text { tumor }\right)\end{array}$ & yes & $\begin{array}{c}250^{*} \\
\text { (2 doses) }\end{array}$ & two & 32.6 \\
\hline 4 & $\mathrm{~F}$ & 68 & 6 & $\begin{array}{l}\text { Simultaneous } \\
\text { removal }\end{array}$ & one & 6 & no & 100 & three & 0.01 \\
\hline 5 & $\mathrm{~F}$ & 46 & NA & 3 months & two & $\begin{array}{c}\text { multifocal } \\
10\left(1^{\text {st }} \text { tumor }\right) \\
3\left(2^{\text {nd }} \text { tumor }\right) \\
1\left(3^{\text {d }} \text { tumor }\right)\end{array}$ & no & 100 & seven & 0.1 \\
\hline 6 & $\mathrm{M}$ & 65 & $\begin{array}{c}\text { NA } \\
\text { invasive }\end{array}$ & 6 months & two & 2 & no & 100 & one & 0.6 \\
\hline
\end{tabular}

TGDC: thyroglossal duct cyst, Ca: carcinoma, RAI: radioactive iodine, NA: not available

*recurrence of TGDC Ca, **on stopping thyroxine 
Table 1. A short history of each patient is presented on page 523 .

\section{Late occurrence of thyroid cancer in a patient with TGDC carcinoma (Patient 1)}

A 28-year old male with a history of TGDC carcinoma was referred to our outpatient clinic after the diagnosis of a thyroid nodule. The patient had had surgical resection of a $3.5 \mathrm{~cm}$ cystic lesion in the anterior part of the neck at the age of 18 that proved to be an $8 \mathrm{~mm}$ TGDC carcinoma confined to the cyst wall. At that point thyroid ultrasound did not indicate abnormalities. No other treatment or follow-up had been recommended to the patient in the following 7 years. On the patient's initiative, a neck ultrasound was performed which showed a $5 \mathrm{~mm}$ solid hypoechoic thyroid nodule in the left lobe; during the following 2 years this nodule doubled in size and developed ill-defined margins and microcalcifications.

At first evaluation in our clinic, a neck ultrasound confirmed the presence of an $11 \mathrm{~mm}$ thyroid nodule and additionally identified a $12 \mathrm{~mm}$ TGDC remnant. Fine needle aspiration cytology (FNAC) of the thyroid nodule was negative for cancer (category II by Bethesda). ${ }^{13}$ Due to suspicious ultrasonographic findings, the patient underwent total thyroidectomy and removal of the TGDC remnant. Histology revealed a $9 \mathrm{~mm}$ papillary carcinoma in the left thyroid lobe and a recurrent papillary carcinoma in the TGDC remnant (Table 1). At this point the patient received ablation with $100 \mathrm{mCi}^{131} \mathrm{I}$. After 2 years of follow-up, the patient is free of local and metastatic disease, as confirmed by ultrasound, whole body scan and stimulated thyroglobulin. ${ }^{16}$

\section{Residual disease after incomplete surgery for TGDC carcinoma (Patient 2)}

A 21-year old female was referred to our department for further evaluation and follow-up after a recent diagnosis of papillary carcinoma arising in a TGDC with cyst wall invasion. The presenting symptom was a lump in the front of the neck. The patient underwent thyroidectomy at the same time, which was negative for malignancy. At this point she was referred to us for further management.

Physical examination revealed a small palpable painless mass at the level of the hyoid bone. Computed Tomography (CT) and Magnetic Resonance Imaging (MRI) scans revealed the presence of a heterogeneous, mainly solid lesion of $2.2 \mathrm{~cm}$ in diameter, suggestive of a TGDC remnant (Figure 1 a-f). Reoperation was recommended and histology identified
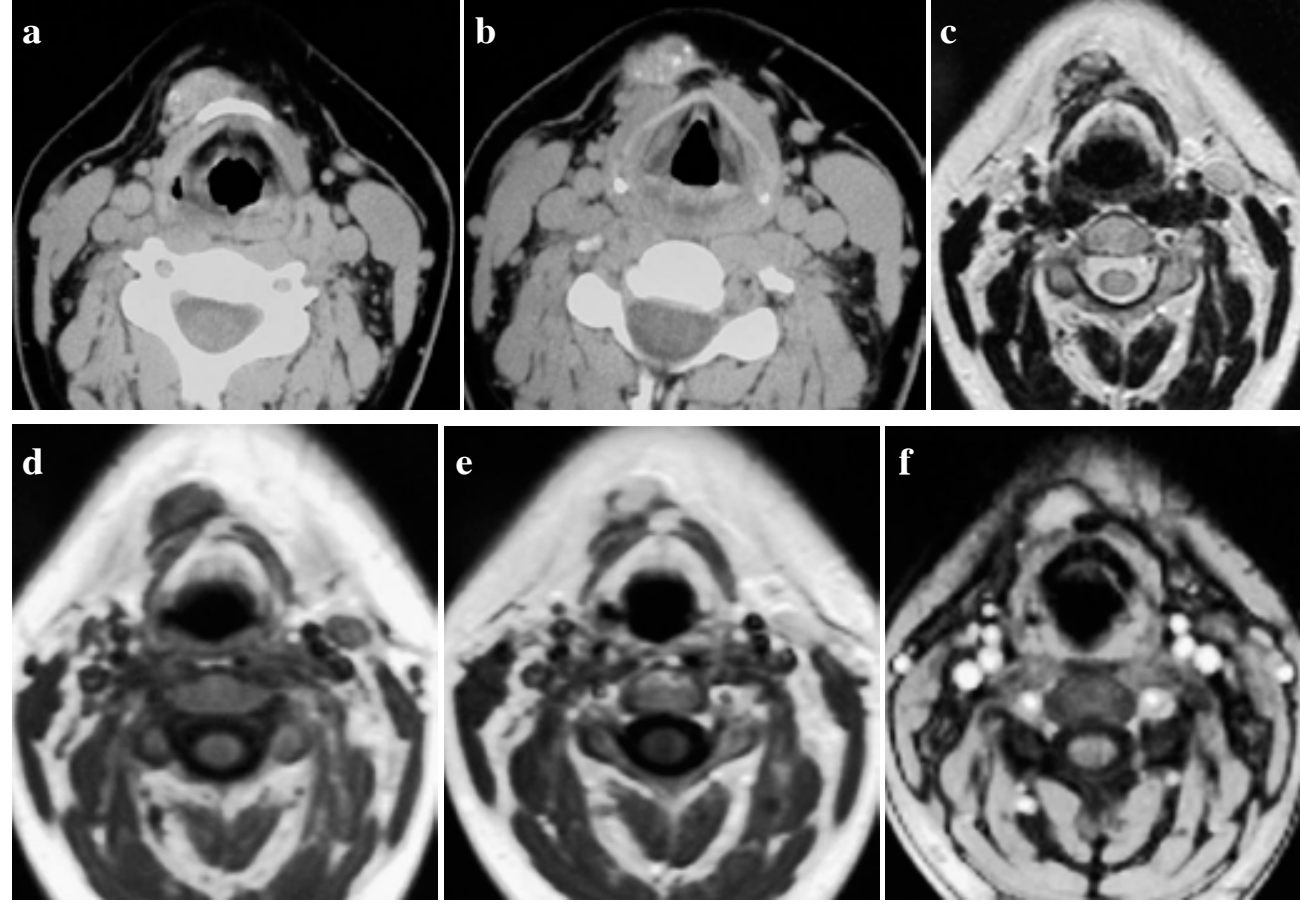

Figure 1 a-f. Axial CT images after IV contrast administration $(\mathrm{a}, \mathrm{b})$ and axial MRI images (c: T2, d: T1, e: T1+ IV contrast, f: T1 fatsat + IV contrast) in patient 2 at the level of the hyoid bone reveal a $2 \mathrm{~cm}$ right paramedian solid mass in direct contact with the anterior surface of the body of the hyoid bone. The mass has internal calcifications in CT $(a, b)$, heterogeneous high signal in T2 (c) and homogenous enhancement $(\mathrm{e}, \mathrm{f})$. 
an invasive $5 \mathrm{~mm}$ papillary carcinoma in the TGDC remnant (Figure $2 \mathrm{a}, \mathrm{b}$ ). Ablation with $100 \mathrm{mCi}$ of ${ }^{131}$ I was given, followed by a second dose 9 months later due to residual local disease (Table 1). During 10 years of follow-up, no recurrences or metastases were identified. She is now on replacement therapy with thyroxine therapy and has recently given birth to her first child.

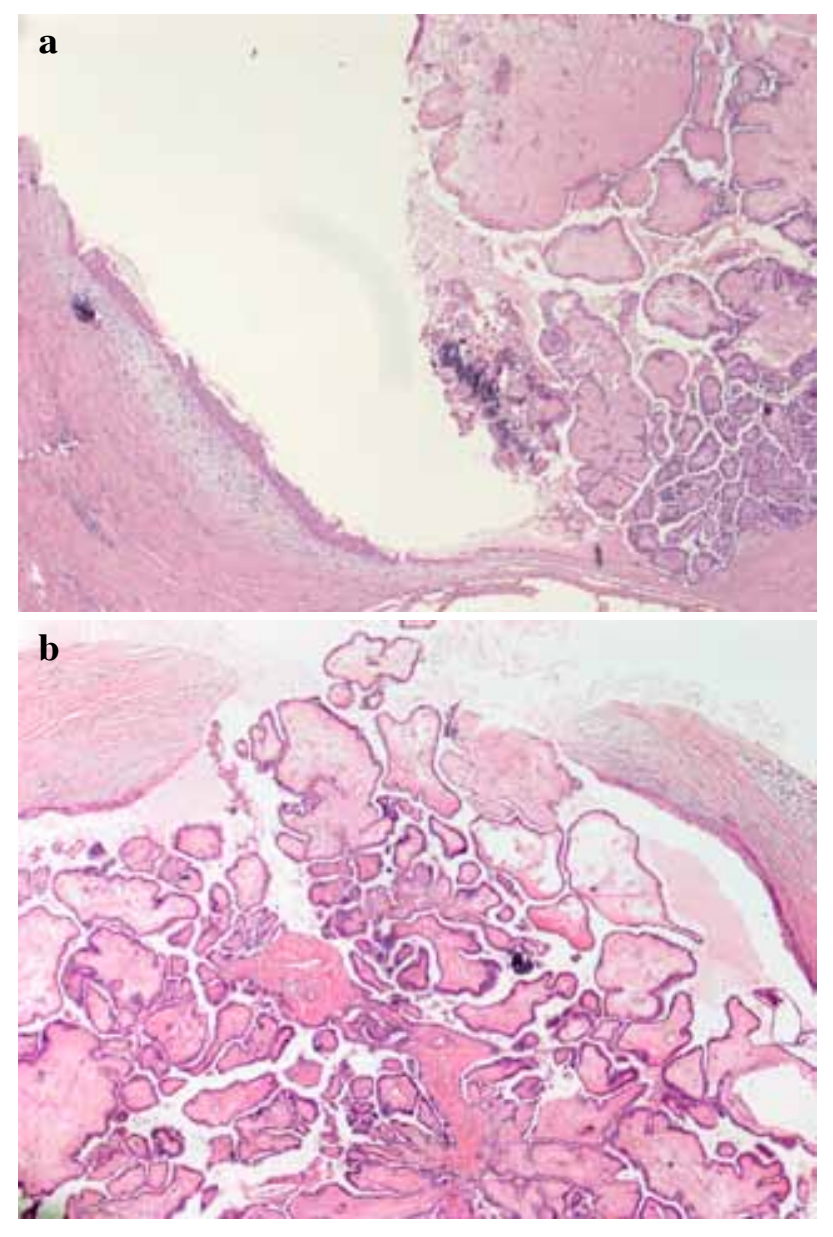

Figure 2 a, b: Histological pictures of patient 2 (HEX 40 for both images). a: The lining of the cyst with squamous cells is shown at the left side. b: Papillary carcinoma within the cyst with psammoma bodies are shown.

\section{Bilateral cervical lymph node metastases in a patient with invasive TGDC carcinoma and thyroid cancer (Patient 3)}

An 18-year old female was referred to our department after removal of a cervical cystic mass located at the level of the hyoid bone, which in histological examination was found to be papillary carcinoma arising in a TGDC invading the surrounding fat tissue. At first evaluation in our outpatients' clinic palpable cervical lymph nodes were identified. Neck ultrasound revealed a goiter with 5 small nodules of maximal diameter up to $1.2 \mathrm{~cm}$ and suspicious bilateral cervical lymph nodes (round shaped with loss of hilum and increased vascularity) at level IV. Total thyroidectomy and modified bilateral lymph node dissection were performed. Histology revealed multifocal, bilateral papillary thyroid microcarcinoma ( 3 and $5 \mathrm{~mm}$ in diameter) and bilateral lymph node metastases (Table 1). She received $250 \mathrm{mCi}$ of radioiodine in 2 doses and thyroxine suppressive therapy. Despite combined treatment, 2 years after the initial diagnosis the patient has residual cervical disease identified by ultrasound. Stimulated Tg levels are increased $(32.6 \mathrm{ng} / \mathrm{ml})$ with $\mathrm{TSH} 110 \mathrm{IU} / \mathrm{ml}$ on discontinuing L-T4. At present, we are contemplating additional RAI therapy, as the patient is reluctant to undergo surgical treatment.

\section{Simultaneous diagnosis of TGDC and thyroid gland microcarcinomas (Patient 4)}

A 68-year old female was referred to our department for evaluation and further treatment. The patient had a 10-year history of multinodular goiter, which had recently been complicated by hyperthyroidism. Additionally, she was followed up for a midline cystic neck mass that had progressively increased in size and was now $3 \mathrm{~cm}$ in its maximal diameter. Ultrasound of the thyroid confirmed the existence of the goiter and the presence of small isoechoic nodules as well as the cystic mass in front of the hyoid bone. Excision of the cystic mass was decided and total thyroidectomy of the hyperfunctioning multinodular gland was performed in parallel. Histology revealed a papillary carcinoma arising in a TGDC of $6 \mathrm{~mm}$ within the cyst wall and the thyroid gland also harboured one focus of papillary $6 \mathrm{~mm}$ microcarcinoma (Table 1 ).

\section{The need for thyroid evaluation before operation for TGDC (Patient 5)}

A 46 year-old female was referred to our department 4 months after the diagnosis of TGDC carcinoma confined to the cyst wall. On clinical examination, the thyroid gland was enlarged and neck ultrasound revealed a multinodular goiter. FNAC of a $12 \mathrm{~mm}$ 
thyroid nodule was suspicious for papillary carcinoma (category $\mathrm{V}$ by Bethesda). The patient underwent total thyroidectomy and histology showed multifocal papillary carcinoma (3 tumour loci of 10.3 and $1 \mathrm{~mm}$ ). After surgery the patient received an ablative dose of $100 \mathrm{mCi}$ of radioactive iodine. His biggest complaint was that the two operations were not performed at the same time.

\section{Preoperative diagnosis of TGDC carcinoma with FNAC (Patient 6)}

A 65-year old male with a recent diagnosis of papillary carcinoma arising in a TGDC, invasive to surrounding fat tissue, was referred to our department for further evaluation and treatment (Figure 3). Pre-

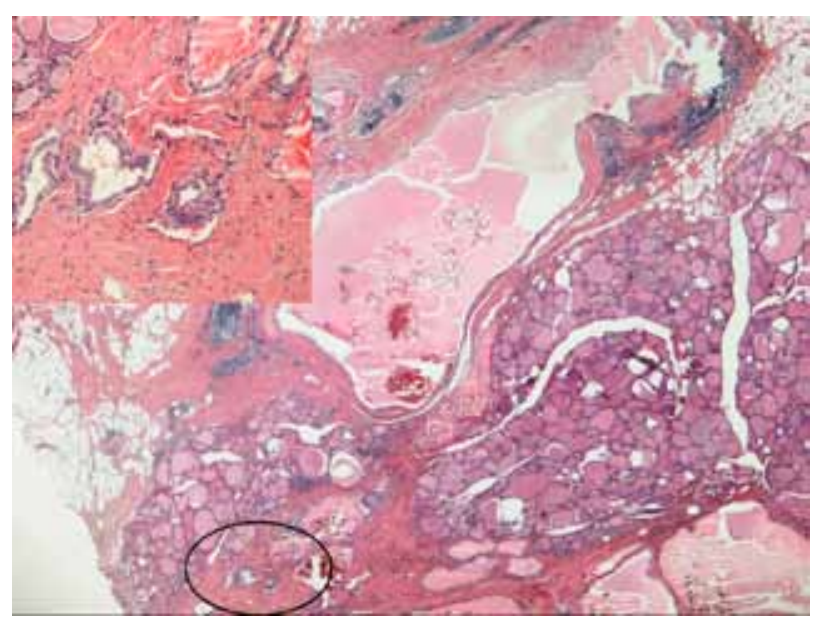

Figure 3. Histological picture of patient 6 (HEX 20 and 40). Neoplastic tissue is shown in the left bottom corner (defined by the circle) and in magnitude in the left upper corner. operatively, the patient had a long-standing growing midline mass, which on CT scans before and after IV contrast was solid with homogeneous enhancement (Figure $4 \mathrm{a}, \mathrm{b}$ ). FNAC of the cyst was suspicious for malignancy (category $\mathrm{V}$ by Bethesda system).

Thyroid ultrasound at presentation showed hypoechoic nodules in both lobes. FNAC of the dominant nodule was negative for malignancy (category II by Bethesda). However, due to the need for RAI therapy of the invasive TGDC carcinoma the patient was referred for total thyroidectomy. Histology revealed a $2 \mathrm{~mm}$ papillary microcarcinoma in the isthmus (Table 1). Subsequently he received ablation with $100 \mathrm{mCi}$ of radioiodine.

\section{DISCUSSION}

In the present study, we report a $66 \%$ co-existence of thyroid cancer after initial diagnosis of TGDC carcinoma. The prevalence of co-existing malignancies in both TGDC and the thyroid increased to $83 \%$ after longer follow-up, as one patient was diagnosed with thyroid cancer 10 years after the TGDC carcinoma diagnosis, a rate that is higher than that reported in other studies..$^{7-9}$ This could be attributed to selection criteria and long-term follow-up, as in 5 of our patients thyroid surgery was decided due to abnormalities in the thyroid gland. Patel et $\mathrm{al}^{8}$ evaluated 5 patients with TGDC carcinoma, this being in addition to the 57 cases published in the literature, and found thyroid carcinoma in $27 \%$. In these cases, thyroid surgery was performed as part of the initial treatment of TGDC
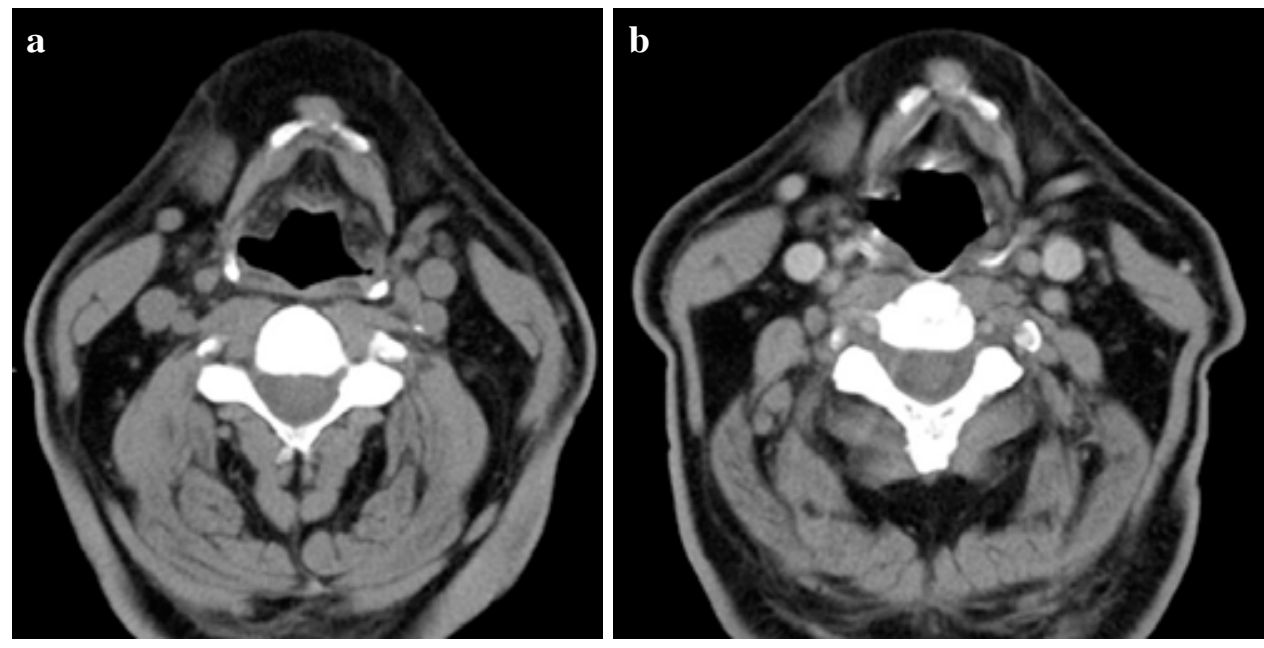

Figure 4 a, b. Axial CT images before (a) and after (b) IV contrast administration in the same patient show a small homogeneously enhancing solid nodule in the midline at the level of the hyoid bone. 
carcinomas and was not based on ultrasonographic findings in the thyroid. Recently, Hartl et $\mathrm{al}^{7}$ reported the co-existence of TGDC carcinoma and thyroid cancer in the order of $56 \%$. In these patients, thyroidectomy was also performed as initial treatment for TGDC carcinoma. Employing a similar approach, Miccoli et $\mathrm{al}^{9}$ found a $33 \%$ co-existence of thyroid cancer in both sites. Even in this series, the reported percentage of thyroid cancer was higher than the $30 \%$ prevalence of occult thyroid carcinomas seen in autopsy series. ${ }^{14}$

It appears that diagnosis of TGDC carcinoma is usually made after surgery. It has been recommended that preoperative aspiration of the cyst and FNAC of the residual mass should be performed in all patients with TGDCs. ${ }^{8,11,12}$ However, due to the hypocellularity of the specimens the diagnostic accuracy of preoperative FNAC may be low. ${ }^{11,15}$ In our series, the decision for surgical treatment of TGDC was based upon gradual increase in cyst size rather than a suspicious FNAC, which was only seen in patient 6 .

An algorithm for TGDC carcinoma treatment has been proposed ${ }^{11}$ Sistrunk's procedure should be the initial approach for patients: a) less than 45 years of age, b) who have tumours less than $1.5 \mathrm{~cm}$ confined to the cyst and c) who have a normal thyroid and neck ultrasound. For patients not fitting these criteria, additional total thyroidectomy (with compartment neck dissection, if applicable) is recommended. In our series, one of our 6 patients (case 1) had local recurrences, possibly due to the use of a simple excision of the thyroglossal cyst and not formal Sistrunk's procedure. The most aggressive manifestation of disease in terms of local infiltration, local recurrence and lymph node metastases was observed in our youngest patients (cases 1 and 3). Based on this observation, we would recommend total thyroidectomy, especially in younger patients, to facilitate follow-up and treatment with RAI, if indicated. All our patients received ${ }^{131} \mathrm{I}$ due to invasive, multifocal or metastatic disease to local lymph nodes. It should be noted, however, that RAI should not be given invariably to all patients, but should rather be used according to established guidelines for differentiated thyroid cancer, ${ }^{16}$ as no specific recommendations exist for TGDC carcinomas. Due to similarities between TGDC carcinoma and papillary thyroid carcinoma (multifocality, sur- rounding soft tissue invasion, lymph node metastases and prognosis), most authors recommend that the management of TGDC carcinoma should be based on current guidelines, as for any other differentiated thyroid cancer. ${ }^{7,12,17}$

One of our patients (case 1) was diagnosed with thyroid carcinoma 10 years after the initial diagnosis of TGDC carcinoma. It is not certain whether a focus of thyroid carcinoma existed at the time of diagnosis of TGDC carcinoma or whether it developed at a later time. Based on ultrasound findings, we believe that the thyroid carcinoma developed later on. The development of thyroid cancer 10 years after the diagnosis of TGDC carcinoma has rarely been reported in the literature. ${ }^{9}$ Three of our patients were younger than 21 years of age, this emphasizing the importance of adequate screening and long-term follow-up in young patients who present with TGDCs. In this series, an increased female to male ratio is seen, as in cases of differentiated thyroid cancer.

The long-standing controversy as to whether thyroid cancer arising in a TGDC represents a metastasis from thyroid cancer or not has not as yet been resolved with certainty, especially in cases of simultaneous discovery of both cancers. In other cases, as in our first patient, the possibility that carcinoma in TGDC is a metastasis is small, as thyroid examination after the TGDC excision did not reveal thyroid morphological abnormalities. Thyroglossal ducts contain, by definition, thyroid epithelium and thus may develop primary cancer. Similarly, it is difficult to identify whether in cases of multifocal thyroid cancer: a) there is a primary thyroid lesion which causes intrathyroidal metastases or b) if all thyroid tumour sites are developed simultaneously and independently from each other.

An interesting point that should be discussed is that, similar to the published series, in our patients the thyroid malignancies were all microcarcinomas. ${ }^{18}$ A plausible explanation for this finding is the fact that during close follow-up after the TGDC carcinoma diagnosis, thyroid cancer is detected and excised earlier. In our series, despite the presence of small size of thyroid tumours, invasive and multifocal thyroid carcinomas were also observed.

One possible weakness of our study is the fact that 
the number of patients is relatively small. However, TGDC carcinoma is a rare entity, with around 250 cases having been published in the world literature. Thus, most published studies are small retrospective case series like our own. Even the most recent series emphasize the weak results of research due to the small numbers of patients. ${ }^{19}$

Based on the available data, we could conclude that ultrasound of the thyroid gland must be performed in all patients. If nodule(s) are identified, further evaluation is recommended. In the event of suspicious ultrasonographic or cytological findings, total thyroidectomy must be applied. Otherwise, long-term follow-up is necessary to exclude the development of thyroid cancer. Further treatment of both cancers must be based on current guidelines for differentiated thyroid cancer.

\section{REFERENCES}

1. Ellis PD, van Nostrand AW, 1977 The applied anatomy of thyroglossal tract remnants. Laryngoscope 87: 765770 .

2. Heshmati HM, Fatourechi V, van Heerden JA, Hay ID, Goellner JR, 1997 Thyroglossal duct carcinoma: report of 12 cases. Mayo Clin Proc 72: 315-319.

3. LiVolsi VA, Perzin KH, Savetsky L, 1974 Carcinoma arising in median ectopic thyroid (including thyroglossal duct tissue). Cancer 34: 1303-1315.

4. Forest V-I, Murali R, Clark JR, 2011 Thyroglossal duct cyst carcinoma:case series. J Otolaryngol Head \& Neck Surgery 40: 151-156.

5. Ein SH, Shandling B, Stephens CA, Mancer K, 1984 The problem of recurrent thyroglossal duct remnants. J Pediatr Surg 19: 437-439.

6. Brown PM, Judd ES, 1961 Thyroglossal duct cysts and sinuses: results of radical (Sistrunk) operation. Am J Surg 102: 494-501.

7. Hartl DM, Al GA, Chami L, Leboulleux S, Schlumberger M, Travagli JP, 2009 High rate of multifocality and occult lymph node metastases in papillary thyroid carcinoma arising in thyroglossal duct cysts. Ann Surg
Oncol 16: 2595-2601.

8. Patel SG, Escrig M, Shaha AR, Singh B, Shah JP, 2002 Management of well-differentiated thyroid carcinoma presenting within a thyroglossal duct cyst. J Surg Oncol 79: 134-139.

9. Miccoli P, Minuto MN, Galleri D, Puccini M, Berti P, 2004 Extent of surgery in thyroglossal duct carcinoma: reflections on a series of eighteen cases. Thyroid 14: 121-123.

10. Falvo L, Giacomelli L, Vanni B, Marzollo A, Guerriero G, De AE, 2006 Papillary thyroid carcinoma in thyroglossal duct cyst: case reports and literature review. Int Surg 91: 141-146.

11. Plaza CP, Lopez ME, Carrasco CE, Meseguer LM, Perucho AL, 2006 Management of well-differentiated thyroglossal remnant thyroid carcinoma: time to close the debate? Report of five new cases and proposal of a definitive algorithm for treatment. Ann Surg Oncol 13: 745-752.

12. Luna-Ortiz K, Hurtado-Lopez LM, Valderrama-Landaeta JL, Ruiz-Vega A, 2004 Thyroglossal duct cyst with papillary carcinoma: what must be done? Thyroid 14: 363-366.

13. Cibas ES, Ali SZ, 2009 The Bethesda system for reporting thyroid cytopathology. Thyroid 19: 1159-1165.

14. Harach HR, Franssila KO, Wasenius VM, 1985 Occult papillary carcinoma of the thyroid. A "normal" finding in Finland. A systematic autopsy study. Cancer 56: 531538.

15. Yang YJ, Haghir S, Wanamaker JR, Powers CN, 2000 Diagnosis of papillary carcinoma in a thyroglossal duct cyst by fine-needle aspiration biopsy. Arch Pathol Lab Med 124: 139-142.

16. Cooper DS, Doherty GM, Haugen BR, et al, 2009 Revised American Thyroid Association management guidelines for patients with thyroid nodules and differentiated thyroid cancer. Thyroid 19: 1167-1214.

17. Mazzaferri EL, 2004 Thyroid cancer in thyroglossal duct remnants: a diagnostic and therapeutic dilemma. Thyroid 14: 335-336.

18. DeLellis RA, Lloyd RV, Heitz PU, Eng C (eds), 2004 WHO classification of tumors: Pathology and Genetics - Tumors of Endocrine Organs. IARC Press, Lyon.

19. Sturniolo G, Moleti M, Violi MA, et al 2012 Prevalence of Thyroglossal Duct Cyst Carcinoma in Adults Having Surgery for Thyroglossal Duct Cysts. Thyroid Jul 24. 